TITLE:

\title{
History of Takayasu arteritis and Dr. Mikito Takayasu.
}

$\operatorname{AUTHOR}(\mathrm{S})$ :

Terao, Chikashi

\section{CITATION:}

Terao, Chikashi. History of Takayasu arteritis and Dr. Mikito Takayasu.. International journal of rheumatic diseases 2014, 17(8): 931-935

\section{ISSUE DATE:}

2014-11

URL:

http://hdl.handle.net/2433/200185

\section{RIGHT:}

This is the peer reviewed version of the following article: Terao, C. (2014). History of Takayasu arteritis and Dr. Mikito Takayasu. International Journal of Rheumatic Diseases, 17: 931-935, which has been published in final form at

http://dx.doi.org/10.1111/1756-185X.12576. This article may be used for non-commercial purposes in accordance with Wiley Terms and Conditions for Self-Archiving.; The full-text file will be made open to the public on 01 Dec 2015 in accordance with publisher's 'Terms and Conditions for Self-Archiving'.; この論文は出版社版でありません。引用の際に は出版社版をご確認ざ利用ください。; This is not the published version. Please cite only the published version. 
History of Takayasu arteritis and Dr. Mikito Takayasu

Chikashi TERAO ${ }^{1}$

${ }^{1}$ Center for Genomic Medicine, Kyoto University Graduate School of Medicine, Kyoto 606-8507, Japan

Correspondence should be addressed to: Chikashi Terao

- Tel : +81-75-366-7405

- Fax : +81-75-751-4167

• E-mail: a0001101@kuhp.kyoto-u.ac.jp

- Address : 53 ShogoinKawahara-cho, Sakyo-ku, Kyoto 606-8507, Japan 
Takayasu arteritis (TAK) is a vasculitis mainly affecting the aorta and its large branches ${ }^{1}$. TAK predominantly affects young women and $90 \%$ of the patients of TAK are females. While many patients with TAK have been found in Asian countries, this disease is reported from all over the world.

In spite of the prevalence of this disease's name, the history of TAK and Dr. Mikito Takayasu, who was the first to report a patient with TAK is not widely known. In this essay, I would like to introduce the history of TAK and Dr. Takayasu.

\section{HISTORY OF TAKAYASU ARTERITIS}

In April 1908, Dr.Mikito Takayasu (Figure 1), a professor of Ophthalmology at the current Kanazawa University, reported a case of a 22-year old woman in the $12^{\text {th }}$ Annual Meeting of Japanese Ophthalmology Society held in Fukuoka. He described “a case of peculiar changes in

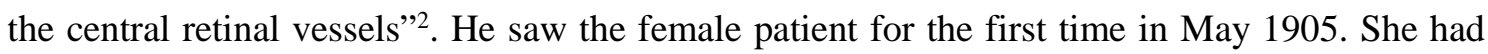
felt lowering and blurring of her vision since September 1904. She sometimes developed redness of conjuctiva. While the symptoms transiently improved by medication, they recurred in March 1905 and she visited Dr. Takayasu. She did not have a history of severe medical or gynecological diseases. While he described that she looked as if she suffered from tuberculosis, 
he and his colleagues in the Department of Internal Medicine did not find any evidence of infection including tuberculosis and syphilis. Her pupils were slightly dilated and the light reflex was damaged. He found eminent abnormalities in retinal vessels. Retinal vessels branched 2 to $3 \mathrm{~mm}$ away from the optic disc and the branches formed anastomosis with one another to create circularity around the disc. The branches further radially branched and the peripheral portions were narrow. The distal parts of the branches made aneurism, anastomosis with other branches to form circularity or terminated in a blind end. The optic disc was severely congested and hemorrhage was found around the disc. While these abnormalities were mainly found in arteries, venous anastomosed with arteries and venous blood flowed into the lesions. While he found these abnormalities in Oculus Dexter (OD), similar findings were reported in Oculus Sinister. She was admitted and took medications. During the first admission, she was found to have cataract and underwent operation. However, her vision did not improve. She stopped visiting hospital for several years after discharge. She revisited his clinic in February 1908. She developed retinal detachment and her left pupil was remarkably dilated. Dr. Takayasu had no choice but to tell her that there was no effective treatment. He described that the anastomosis and aneurismal changes should be the primary findings and that the others should be the secondary findings. After his presentation at the Congress, Dr. Yoshiakira Ohnishi, a professor at Kyushu University, mentioned another female case resembling the case presented 
by Dr. Takayasu. He described that he could not sense her pulse at the bilateral radial arteries.

This case report by Dr. Takayasu was published in June in the same year in the Journal of the Juzen Medical Society in Kanazawa University (Figure 2). In this manuscript, he presented an image of the arteries that he beautifully hand-sketched himself (Figure 3).

While it is often regarded that it was Dr. Takayasu who first reported a patient with TAK, there are other prior potential case reports of patients with TAK. Giovanni Battista Morgagni, an Italian anatomist, described a 40-year-old female suffering from pulseless disease ${ }^{3}$. In 1830, Rokushu Yamamoto described a 45-year-old male suffering from fever ${ }^{4}$. After one year, the patient became pulseless in right radial artery and had a very weak pulse in left radial artery. The patient developed pulseless in both carotid arteries and died 11 years after the first visit. He described two other cases reported by another doctor. In 1856, Savory reported a 22-year-old female presenting pulseless in both upper extremities and left neck ${ }^{5}$. The patient lost her vision. However, whether these cases truly suffered from TAK is uncertain. Numano suspected the case reported by Savory should be explained by other diseases since the patient had cornea ulcer leading to invasion of scalp and brain ${ }^{4}$.

Dr. Minoru Nakajima in 1921 compared his cases with previous reports and proposed that they should be regarded as one disease. He characterized this disease by the following four criteria; 
1) affect bilateral eyes in young women, 2) arteriovenous anastomosis around the optic disc and microaneurysm formation in retinal vessels, 3) lowering of vision complicated with cataract, 4) unpalpable radial artery. He proposed to call this disease “Takayasu disese”. After his proposal, Japanese ophtalmologists paid attention to this disease and many cases were reported. In 1946, Frövig proposed that the diseases presenting pulselessness should be called "Aortic arch

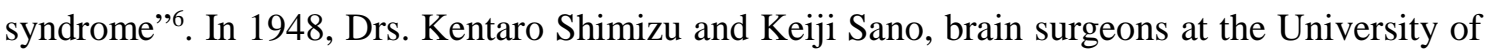
Tokyo, proposed to give an alias name of 'pulseless disease'. In 1951, this disease was reported by these doctors outside of Japan for the first time, by reviewing a total of 25 cases $^{7}$. Since 1951, there have been case reports from a number of foreign countries. In 1952, Caccamise and Whitman reported the primary occidental case report. ${ }^{8}$ In 1962, Judge et al described “Takayasu’s arteritis”. In Japan, many doctors proposed acronyms of TAK. Drs. Maekawa and Kakei called it "occlusive coagulant aortic syndrome"10. Dr. Nasu called it 'Obstructive productive arteritis' ${ }^{11}$. In 1965, Riehl et al analyzed this disease from pathological and immunological aspects and proposed the concept that this disease is an autoimmune disease ${ }^{12}$. Since 1990 when the American College of Rheumatology published a classification criteria of TAK $^{13}$ and described "Takayasu arteritis", the name of TAK prevailed worldwide. Although both "Takayasu arteritis“ and "Takayasu's arteritis” are used, in the Online Mendelian Inheritance in Man (OMIM) it is registered as "Takayasu arteritis" and this expression is more 
commonly used.

The case report by Dr. Takayasu is quite suggestive. His report tells us that we should carefully examine and observe patients to find characteristics of the patients. Even if we saw just one case, there is a possibility that many patients exist with the same symptoms. It is impressive that Dr. Takayasu described the first patient as being similar to patients with tuberculosis. In fact, there are studies pointing out the overlapping of TB and TAK ${ }^{14,15}$. Geographical prevalence of TAK is similar to that of TB. Although there are many conflicting studies in terms of epidemiology and immunology ${ }^{16}$, there is a possibility that exposure to TB triggers the immune reaction to TAK. In fact, my group showed that the susceptibility variant is located in the $I L 12 B$ region ${ }^{17}$ and this variant has previously been reported in relation to mycobacterium infection.

\section{HISTORY OF Dr. MIKITO TAKAYASU}

Dr.Mikito Takayasu was born on $19^{\text {th }}$ July 1860 in Saga prefecture in Japan as the fourth son of a priest. He graduated from Tokyo foreign language school and entered Tokyo University. He was then adopted by Dr. Takayasu. He graduated from Tokyo University in 1887 and soon moved to Kanazawa prefecture as a lecturer. He went to Germany for two years, where he performed research in Berlin City hospital, Berlin Charité University Hospital and Leipzig 
University. He studied under Dr.von Graphe. He showed by means of Sudan dyes that arcus senilis occurs due to fat deposition ${ }^{18}$. Until his findings, little was known about nature of arcus senilis in spite of the high frequency of this phenomenon. He returned to Kanazawa and obtained his Ph.D. degree in 1903 for this research. He then went on to become a professor and principal of the medical school. In 1923, the medical school was reorganized as Medical University and he was appointed to Dean. He retired from University in 1924. After retirement, he opened his own clinic near the University Hospital. To prevent the lowering in numbers of patients in surrounding ophthalmologist clinics, he set a very expensive doctor's fee. Despite of the expensive fees, his clinic was very popular because patients highly appreciated his sound character and respected his medical skills, experience, and knowledge. It is said that many people believed that water from the small river running by his house was effective for eye diseases. In 1933, he suffered from stroke and moved to Beppu in Kyushu for recovery. He died of rectal cancer in Beppu when he was 78 years old on $20^{\text {th }}$ November, 1938 . His bones were transferred to Kanazawa soon after his death and his funeral was conducted in Kanazawa University. His grave has been kept in Hoenji Temple near Kanazawa University (Figure 4). His statue was built in Kanazawa University in 2002 (Figure 5). He had three sons and five daughters. Dr. Akira Takayasu, his $2^{\text {nd }}$ son was a professor of Ophthalmology at Kagoshima University. Dr. Tatsuo Hirose, his great-grandson is a clinical professor of Ophthalmology at 
Harvard Medical School. Dr. Hirose is a grandson of Ms. Miyako Takayasu Hirose, one of Dr.

Takayasu's daughters. According to Dr. Hirose, he had seen a couple of young women with TAK during his four-year stay in the Ophthalmology Clinic in Kanazawa University. However, he has not seen a single patient with TAK in Boston during his carrier over forty years in a tertiary referral retina clinic in Boston. This can be explained by different prevalence of TAK among different populations. 
Figure 1. Portrait of Dr. Mikito Takayasu

Figure 2. The manuscript of the first case with TAK by Dr. Mikito Takayasu.

Figure 3. Hand-sketch by Dr. Mikito Takayasu for the inverted image of fundus in OD from the first case.

Figure 4. Dr. Mikito Takayasu’s grave in Hoenji Temple near Kanazawa University.

Figure 5. A statue of Dr. Mikito Takayasu in Kanazawa University.

Acknowledgement: I would like to thank Dr. Tatsuo Hirose in the Ophthalmology Department of Harvard Medical School and Dr. Kazuki Kuniyoshi in the Department of Ophthalmology, Kinki University Faculty of Medicine, for allowing me to include information of Dr. Hirose in this assay and for their kind help to obtain information about Dr. Mikito Takayasu. I would like to thank Dr. Kazuhisa Sugiyama in the Ophthalmology Department of Kanazawa University for allowing me to use their photos for this essay.

\section{Reference}

1. Terao C, Yoshifuji H, Mimori T. (2014) Recent advances in Takayasu arteritis. Int J Rheum Dis. 17(3), 238-47.

2. Sugiyama K, Ijiri S, Tagawa S, Shimizu K. (2009) Takayasu disease on the centenary of its discovery. Jpn J Ophthalmol. 53(2), 81-91.

3. Lazzarin P, Pasero G, Marson P, Cecchetto A, Zanchin G. (2005) [Takayasu's arteritis. A concise review and some observations on a putative case reported by Giovanni Battista Morgagni (1761)]. Reumatismo. 57(4), 305-13.

4. Numano F. (2002) The story of Takayasu arteritis. Rheumatology (Oxford). 41(1), 103-6.

5. Savory WS. (1856) Case of a Young Woman in whom the main Arteries of both Upper Extremities and of the Left Side of the Neck were throughout completely Obliterated. Med Chir Trans. 39, 205-19.

6. Frövig AG. (1946) Bilateral obliteration of the common carotid artery. Acta psychiat suppl., 39 .

7. Shimizu K, Sano K. (1951) Pulseless disease. J Neuropathol Exp Neurol. 1(1), $37-47$.

8. Caccamise WC, Whitman JF. (1952) Pulse-less disease; a preliminary case report. Am Heart J. 44(4), 628-33.

9. Judge RD, Currier RD, Gracie WA, Figley MM. (1962) Takayasu's arteritis and the 
aortic arch syndrome. Am J Med. 32, 379-92.

10. Maekawa M KY. (1958) The pulseless disease: report of a specific case. Jpn Circ J. $22,196$.

11. Nasu T. (1968) [Pathohistological changes and etiology of obstructive productive arteritis]. Nihon Rinsho. 26(11), 3292-9.

12. Riehl JL, Brown WJ. (1965) Takayasu's Arteritis: An Auto Immune Disease. Arch Neurol. 12, 92-7.

13. Arend WP, Michel BA, Bloch DA, Hunder GG, Calabrese LH, Edworthy SM, et al. (1990) The American College of Rheumatology 1990 criteria for the classification of Takayasu arteritis. Arthritis Rheum. 33(8), 1129-34.

14. Aggarwal A, Chag M, Sinha N, Naik S. (1996) Takayasu's arteritis: role of Mycobacterium tuberculosis and its $65 \mathrm{kDa}$ heat shock protein. Int J Cardiol. 55(1), 49-55.

15. Hong CY, Yun YS, Choi JY, Sul JH, Lee KS, Cha SH, et al. (1992) Takayasu arteritis in Korean children: clinical report of seventy cases. Heart Vessels Suppl. 7, 91-6.

16. Jain S, Kumari S, Ganguly NK, Sharma BK. (1996) Current status of Takayasu arteritis in India. Int J Cardiol. 54 Suppl, S111-6.

17. Terao C, Yoshifuji H, Kimura A, Matsumura T, Ohmura K, Takahashi M, et al. (2013) Two susceptibility loci to Takayasu arteritis reveal a synergistic role of the IL12B and HLA-B regions in a Japanese population. Am J Hum Genet. 93(2), 289-97.

18. Takayasu M. (1901) Beiträge zur pathologische Anatomie des Arcus senilis. Arch Augenh. 43, 154-62. 


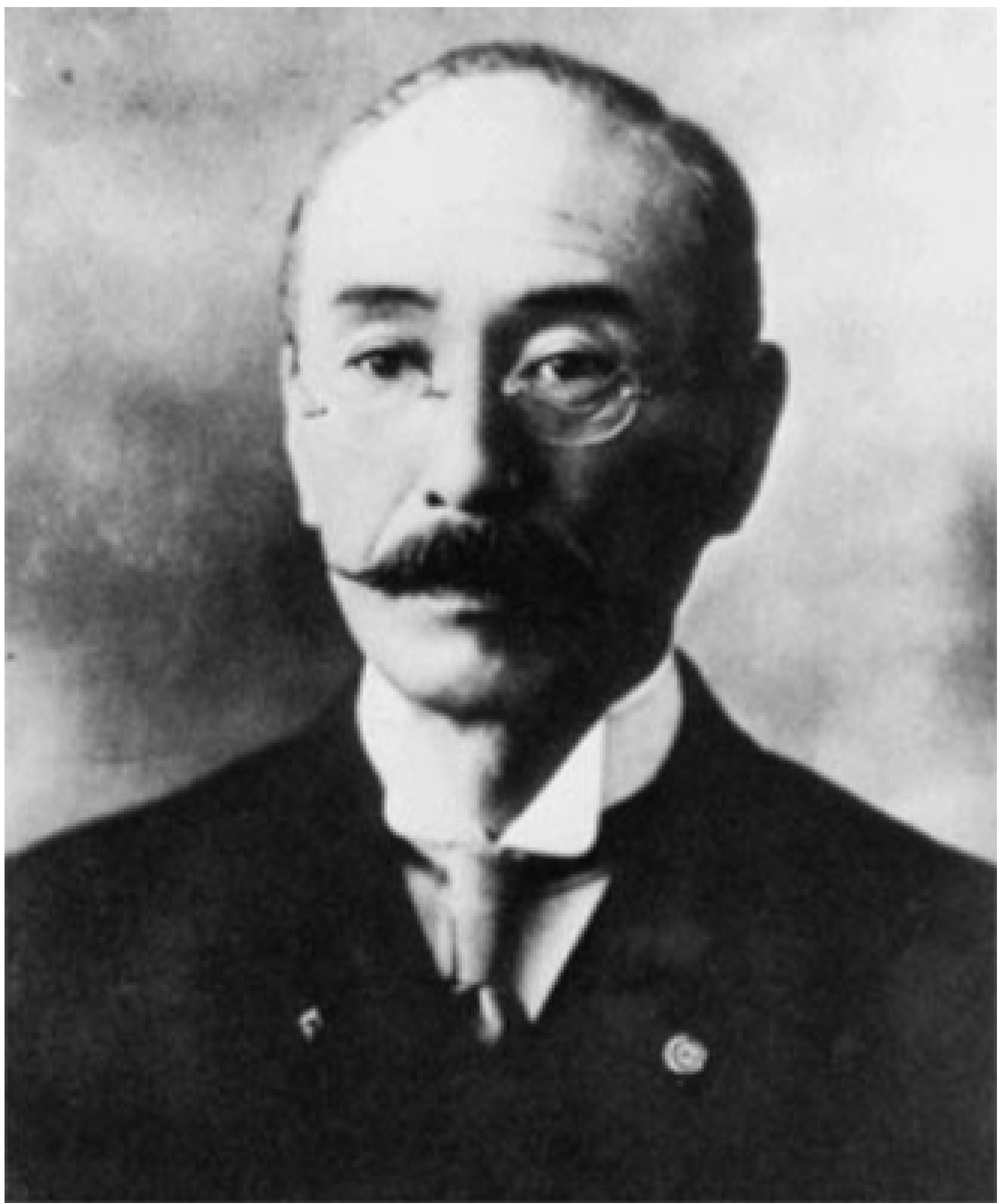

Figure 1 


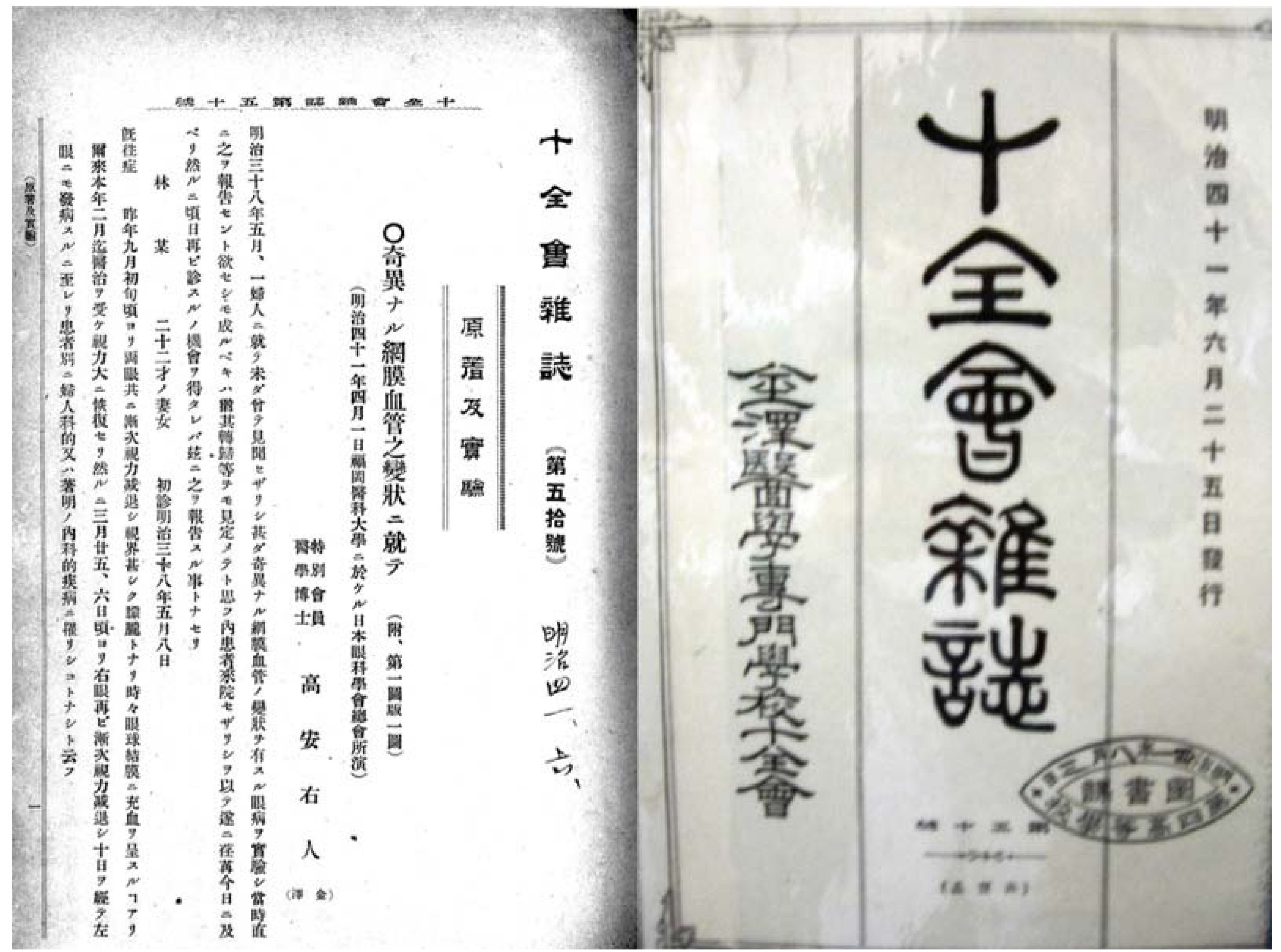

Figure 2 
版圖壹第

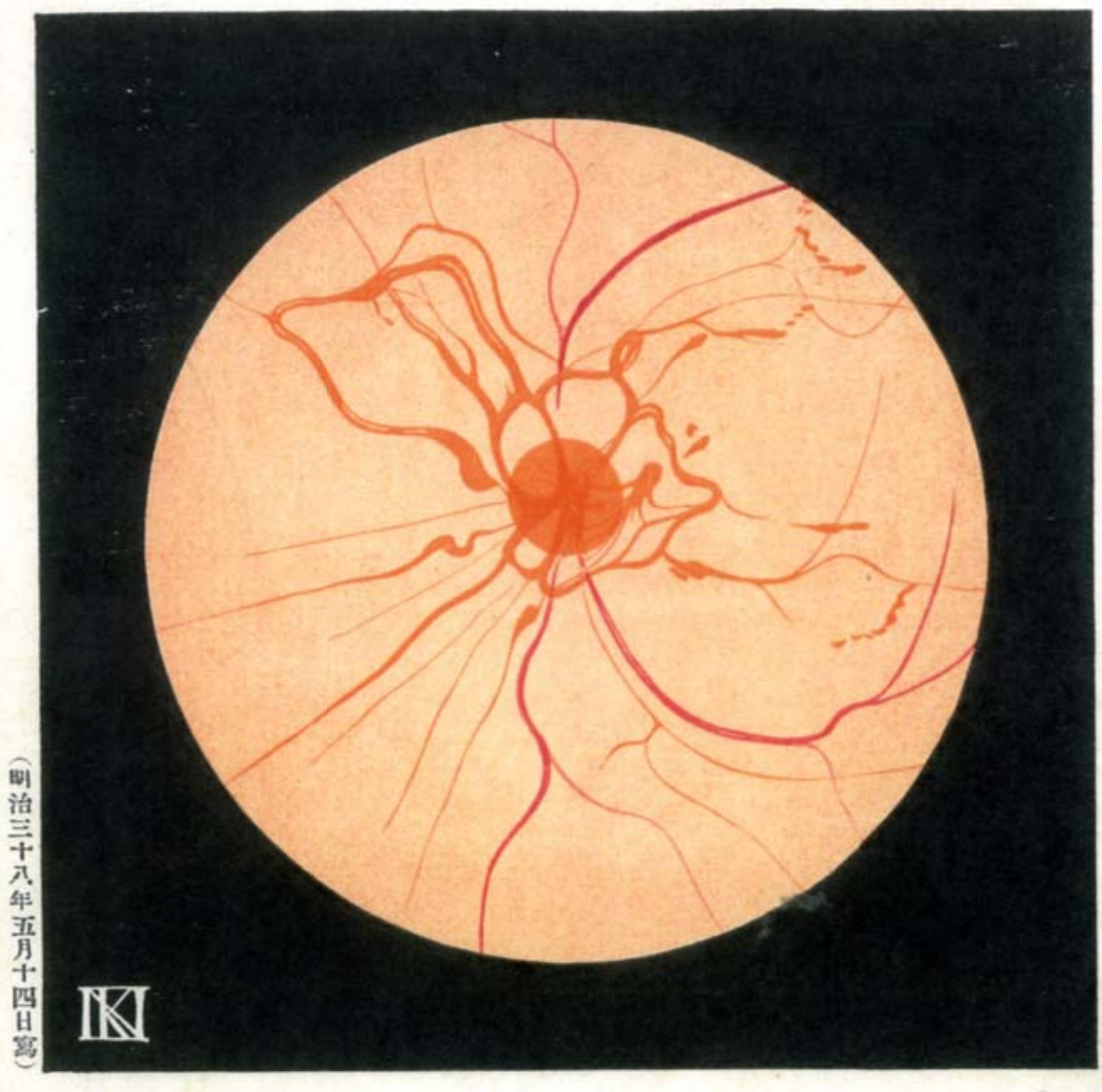

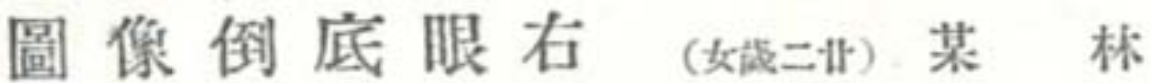

Figure 3 


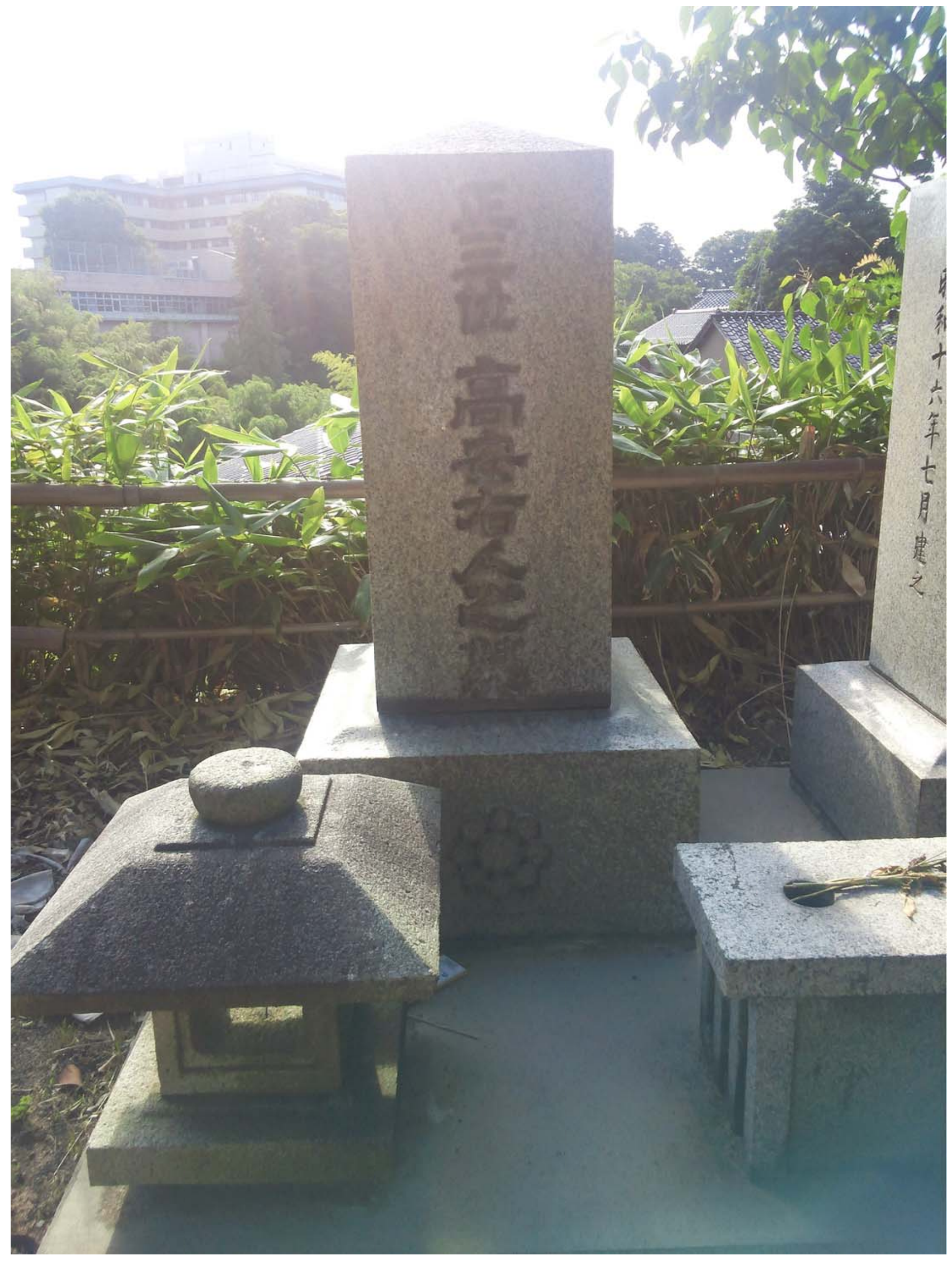

Figure 4 


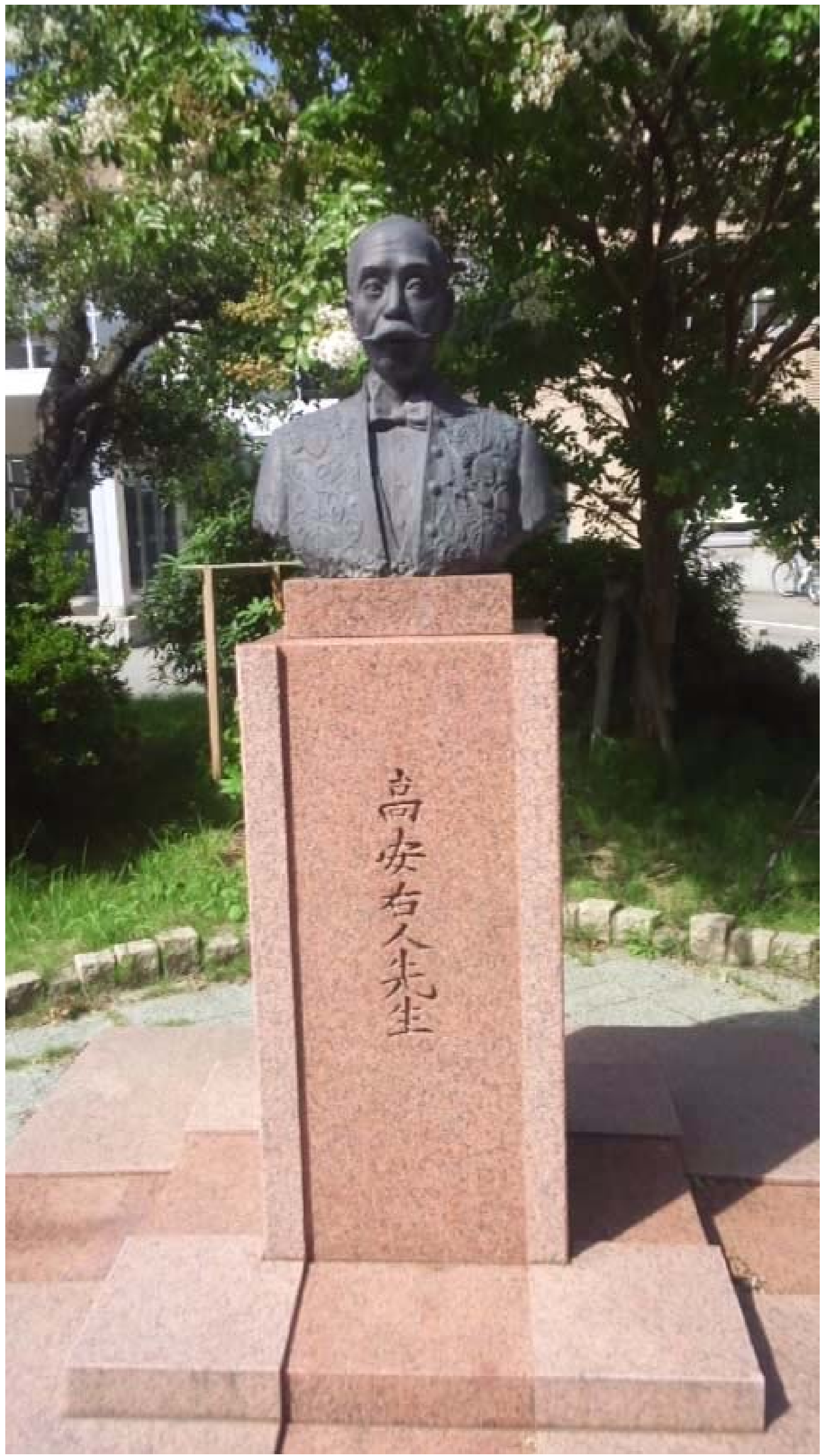

Figure 5 